\title{
Expression of Notch1 and mTOR pathway proteins in pediatric lymphoblastic lymphoma; a Children's Oncology Group report
}

\author{
Kristi J. Smock • Archana M. Agarwal • Megan S. Lim • Sheryl R. Tripp • \\ Rodney R. Miles • Jay L. Patel • Minnie Abromowitch • Mark A. Lones • \\ Mitchell S. Cairo • Sherrie L. Perkins
}

Received: 5 September 2013 / Accepted: 12 February 2014 / Published online: 27 February 2014

(C) Springer-Verlag Berlin Heidelberg 2014

\begin{abstract}
Acute lymphoblastic leukemia (ALL) and lymphoma (LBL) represent a disease spectrum. Activating mutations in Notch1 are found in 50-60\% of T-cell ALL, and little is known about its role in B-cell ALL. Notch1 activation results in upregulation of the mammalian target of rapamycin (mTOR) pathway. Expression of mTOR and downstream targets has not been characterized in LBL. We analyzed immunohistochemical expression of Notch1, phospho-mTOR, phospho-70S6 kinase, and phospho-S6 ribosomal protein in 15 cases of T-cell LBL and 10 cases of B-cell LBL obtained from Children's Oncology Group trial CCG 5971. Positive specimens were defined as $\geq 25 \%$ expression. All specimens expressed Notch1 and most expressed phospho-mTOR and phospho-70S6 kinase, while a minority expressed phosphoS6 ribosomal protein. Our data suggest that expression of both
\end{abstract}

Kristi J. Smock and Archana M. Agarwal contributed equally to this paper.

K. J. Smock · A. M. Agarwal • R. R. Miles · S. L. Perkins Department of Pathology, University of Utah Health Sciences Center, 15 North Medical Drive East, Salt Lake City, UT 84112, USA

K. J. Smock · A. M. Agarwal · S. R. Tripp · R. R. Miles •

S. L. Perkins

ARUP Institute for Clinical \& Experimental Pathology, 500 Chipeta Way, Salt Lake City, UT 84108, USA

M. S. Lim

Department of Pathology, University of Michigan, 1301 Catherine, 5240 Medical Science I, Ann Arbor, MI 48109, USA

\section{J. L. Patel}

Department of Pathology, Stanford University School of Medicine, 300 Pasteur Drive, Lane 235, Stanford, CA 94305, USA

\section{Abromowitch}

Department of Pediatric Hematology/Oncology, University of Nebraska Medical Center, 982168 Nebraska Medical Center, Omaha, NE 68198, USA the Notch1 and mTOR pathways are increased in T-cell and B-cell pediatric LBL and support further studies in determining the therapeutic role of Notch1 and mTOR inhibitors.

Keywords Acute lymphoblastic leukemia (ALL) . Lymphoblastic lymphoma(LBL) · Notch $1 \cdot$ Mammalian target of rapamycin $(\mathrm{mTOR}) \cdot$ Immunohistochemistry

\section{Introduction}

Acute lymphoblastic leukemia (ALL) and lymphoblastic lymphoma (LBL) are thought to represent a disease spectrum differentiated primarily based on the percentage of blood and bone marrow blasts. By definition, the term lymphoma

\section{A. Lones}

Department of Pathology and Laboratory Medicine, University of California Los Angeles, 10833 Le Conte Avenue, Center for Health Science, Room 13-222, Los Angeles, CA 90095, USA

M. S. Cairo

Departments of Pediatrics, Medicine, Pathology, Microbiology \& Immunology, and Cell Biology \& Anatomy, New York Medical College, 50 Plaza West, Munger Pavilion, Room 110, Valhalla, NY 10595, USA

K. J. Smock $(\bowtie)$

Department of Pathology, ARUP Laboratories, University of Utah, 500 Chipeta Way, Mail Stop 115-G04, Salt Lake City, UT 84108,

USA

e-mail: Kristi.Smock@aruplab.com 
is used when the neoplastic process is confined to a mass lesion with no or minimal involvement of the peripheral blood or bone marrow [1]. These neoplasms are divided into T-ALL/ LBL and B-ALL/LBL based on the lineage commitment of the lymphoblasts. While B-ALL is seen predominantly in children, T-ALL is seen frequently in adolescents and has a worse prognosis compared to the B-ALL [1]. T-LBL comprises approximately $85-90 \%$ of all pediatric LBL and frequently presents as a mediastinal mass.

Activating mutations in Notch1, a transmembrane protein that plays an important role in T-cell development, are found in 50-60\% of T-ALL [2]. There are four types of Notch transmembrane receptors, termed Notch 1-4 which can interact with Delta-like ligands 1, 3, and 4, and Jagged 1 and 2. Notch 1 is a single-pass heterodimeric transmembrane receptor. Its extracellular subunit mediates ligand binding that leads to proteolytic cleavage and release of the intracellular domain. The intracellular domain then enters the nucleus and takes part in transcriptional activity [3]. Only a limited number of downstream targets of Notch 1 have been described. These include hairy and enhancer of split (HES), HES-related protein (HERP), c-Myc, p21, and p26 [4]. Notch1 is also a key regulator of human T-LiC (leukemia-initialing cells) activity [5].

Recent studies indicate that Notch1 activation results in upregulation of the mammalian target of rapamycin (mTOR) pathway through a number of possible intermediate signaling pathways, including the PI3 kinase/AKT pathways and c-Myc [6]. mTOR is a serine-threonine protein kinase present in all mammalian cells that controls a significant proportion of cellular translational activity, with resultant downstream effects on critical cellular functions such as cell growth, proliferation, and protein synthesis $[7,8]$.

Mammals form two distinct targets of rapamycin complexes (mTORC1 and mTORC2) [9]. mTORC1, a complex of mTOR, raptor (regulatory associated protein of mTOR), and $\mathrm{mLST}$, is inhibited by rapamycin, an immunosuppressive agent obtained from bacteria. mTORC1 has a major role in protein synthesis. The major components of $\mathrm{mTORC} 2$ are mTOR, rictor (rapamycin-independent companion of mTOR), and mLST8. In contrast to mTORC1, mTORC2 is usually resistant to rapamycin. mTORC2 contributes to AKT activation, forming an autoregulatory loop that results in further mTOR activation [9]. mTOR-mediated translational regulation is achieved through phosphorylation of direct targets $\mathrm{p} 70$ ribosomal S6 kinase (p70) and eukaryotic initiation factor 4E binding protein 1 (4EBP1). p70 then directly phosphorylates ribosomal protein $\mathrm{S} 6$ (S6), leading to translation of messenger RNAs (mRNAs) with 7-methyl guanine caps. mTOR dysregulation has been identified in many human malignancies including hematologic malignancies, metabolic disorders, and benign tumor syndromes [10-16]. A simplified diagram of the Notch1 and mTOR signaling pathways is shown in
Fig. 1. In hematologic malignancies, expression of mTOR pathway proteins by immunohistochemistry has been identified in anaplastic large cell lymphoma (ALCL), where increased expression of p-mTOR, p-p70, and p-S6 were noted [17], and in follicular lymphoma cases where increased expression of p-p70 was seen [18].

Expression of the mTOR signaling pathway proteins has not been previously characterized in LBL by immunohistochemistry. We evaluated the expression of Notch1 and mTOR pathway proteins in biopsy samples of precursor-T and precursor-B LBL using phosphorylation of mTOR and downstream proteins as surrogates of mTOR activity.

\section{Materials and methods}

Case selection Fifteen cases of T-LBL and 10 cases of B-LBL were obtained from the archival material of the Children's Oncology Group (COG) clinical trial CCG 5971 for treatment of disseminated LBL using ALL-type therapy [19]. Cases were classified as T-LBL or B-LBL according to study protocol definitions. Patient identifiers were removed prior to the study, and clinical information was not available. All studies were approved by the local institutional review board (IRB) and were conducted in accordance with the Declaration of Helsinki.

Immunohistochemical staining Immunohistochemical stains for Notch1, phospho-mTOR (p-mTOR), phospho-70S6 kinase (p-p70), and phospho-S6 ribosomal protein (p-S6) using commercially available antibodies (Cell Signaling Technology, Danvers, MA, USA) were performed on representative sections of formalin-fixed, paraffin-embedded tumor tissue (lymph node or soft tissue mass) in all 25 cases following heat-induced epitope retrieval (HIER). Antibody staining was performed using a Ventana ES automated strainer (Ventana, Tucson, AZ, USA). All stains had appropriate staining positive and negative controls. Antibody clone, dilution used, and staining pattern characteristics are listed in Table 1.

Interpretation Immunohistochemical stains were assessed independently by three authors (KJS, AMA, and MSL). Specimens were classified as positive if $\geq 25 \%$ of neoplastic cells demonstrated positive staining, based on the average of the three assessments. Final designation of cases as positive or negative required classification agreement of at least two of three authors. The cutoff of $25 \%$ was chosen as it far exceeded any staining observed in the negative control tissues for each stain. Intensity of staining (weak, moderate, strong) was also noted (using positive controls as a guideline), but was not used as a criterion for classification of the cases as positive or negative for a given marker. 
Fig. 1 Notch1 and mTOR signaling pathways

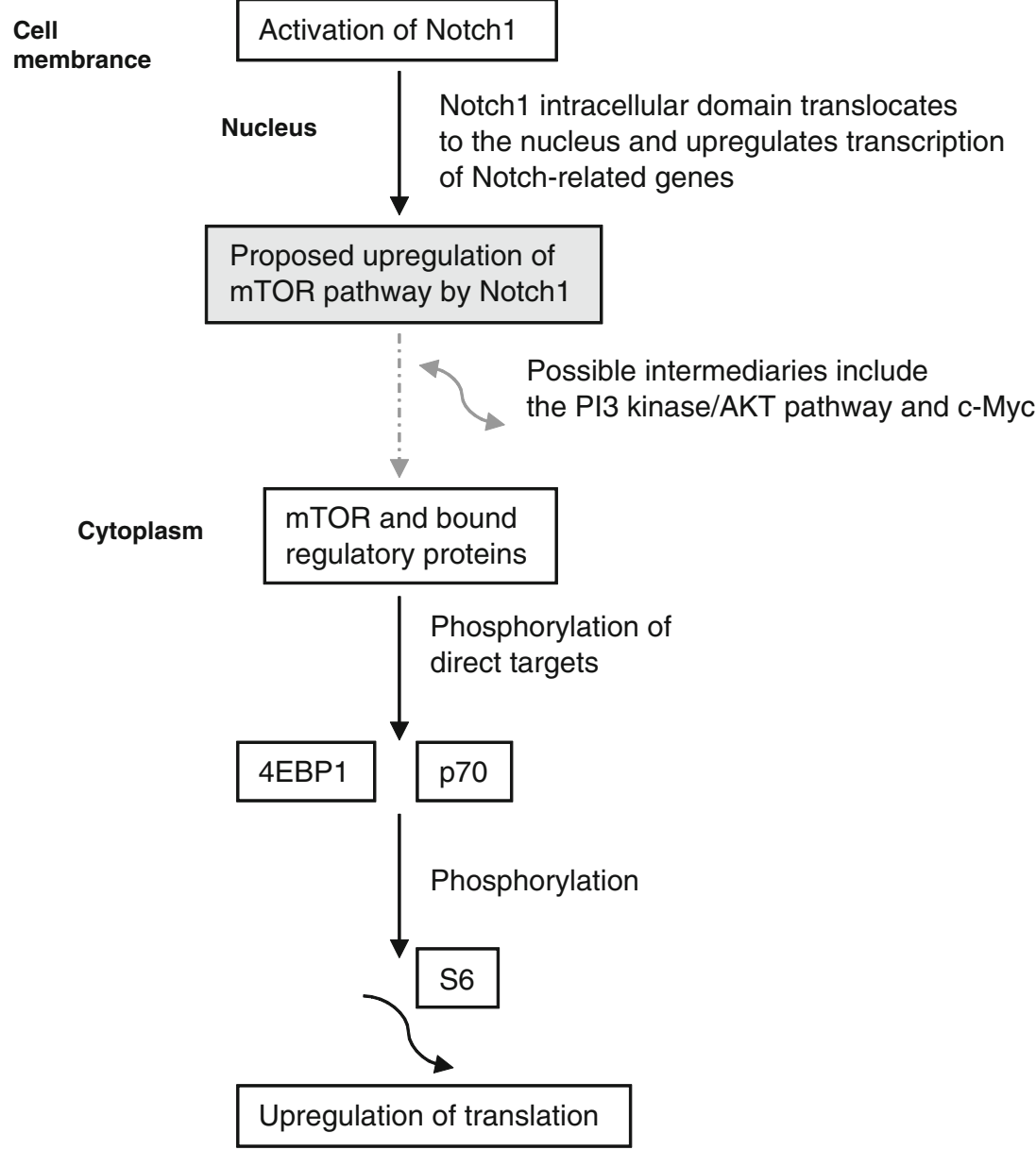

\section{Results}

Results of the immunohistochemical stains are shown in Table 2 and Fig. 2. We observed high expression of Notch1, p-mTOR, and p-p70 in LBL, with all cases demonstrating positive Notch1 staining (100\% of cases demonstrated classification agreement between the three reviewing authors) and $60 \%$ of both T-LBL ( 9 of 15) and B-LBL (6 of 10) cases positive for all three of these markers. Notch1 demonstrated moderate to strong intensity nuclear/cytoplasmic staining in $100 \%$ of cells in all cases. p-mTOR ( $80 \%$ of T-LBL and $70 \%$ of B-LBL) demonstrated weak to moderate intensity

Table 1 Antibodies used for immunohistochemical staining

\begin{tabular}{llll}
\hline Antibody & Clone & Dilution & Staining pattern \\
\hline Notch1 & Val1744 & $1: 20$ & Nuclear/cytoplasmic \\
p-mTOR & Ser2448 (49F9) & $1: 50$ & Cytoplasmic \\
p-p70 & Thr421/Ser424 & $1: 50$ & Nuclear/cytoplasmic \\
p-S6 & Ser235/236 & $1: 1,000$ & Cytoplasmic \\
\hline
\end{tabular}

cytoplasmic staining in $\geq 80 \%$ of cells in most of the positive cases, and there was classification agreement between the three authors in $73 \%$ of T-LBL and $80 \%$ of B-LBL cases. For pp70-positive cases (73\% of T-LBL, $80 \%$ of B-LBL), percentage of positive cells ranged from 30 to $80 \%$, and there was classification agreement between the three authors in $100 \%$ of T-LBL and $90 \%$ of B-LBL cases. Most positive cases demonstrated weak to moderate intensity nuclear/cytoplasmic staining, although a small subset demonstrated strong intensity staining. In cases where one of three authors disagreed on the final classification, the discordant designation generally demonstrated values very close to the cutoff for positivity.

p-S6 demonstrated positive staining in only $27 \%$ of T-LBL cases and $10 \%$ of B-LBL cases. Most positive specimens demonstrated strong cytoplasmic staining with staining in less than $50 \%$ of cells. For p-S6, there was classification agreement between the three authors in $67 \%$ of T-LBL and $60 \%$ of B-LBL cases. As with the other stains, any discordant classifications demonstrated borderline values close to the cutoff for positivity. Specimens that were positive for p-S6 demonstrated a variety of staining patterns for the other markers, and no trends were noted. Ten of 11 T-LBL p-S6-negative cases 
Table 2 Summary of results

\begin{tabular}{|c|c|c|c|c|}
\hline & Notch1 & p-mTOR & p-p70 & p-S6 \\
\hline \multicolumn{5}{|c|}{ T-LBL cases } \\
\hline 1 & Positive & Positive & Negative & Positive \\
\hline 2 & Positive & Positive & Negative & Negative \\
\hline 3 & Positive & Positive & Positive & Positive \\
\hline 4 & Positive & Negative & Positive & Positive \\
\hline 5 & Positive & Positive & Positive & Negative \\
\hline 6 & Positive & Positive & Positive & Negative \\
\hline 7 & Positive & Positive & Positive & Positive \\
\hline 8 & Positive & Positive & Positive & Negative \\
\hline 9 & Positive & Positive & Positive & Negative \\
\hline 10 & Positive & Negative & Positive & Negative \\
\hline 11 & Positive & Positive & Positive & Negative \\
\hline 12 & Positive & Negative & Negative & Negative \\
\hline 13 & Positive & Positive & Positive & Negative \\
\hline 14 & Positive & Positive & Positive & Negative \\
\hline 15 & Positive & Positive & Negative & Negative \\
\hline Total & 15/15 (100\%) & $12 / 15(80 \%)$ & $11 / 15(73 \%)$ & $4 / 15(27 \%)$ \\
\hline \multicolumn{5}{|c|}{ B-LBL cases } \\
\hline 1 & Positive & Positive & Positive & Negative \\
\hline 2 & Positive & Positive & Positive & Negative \\
\hline 3 & Positive & Positive & Positive & Negative \\
\hline 4 & Positive & Positive & Negative & Positive \\
\hline 5 & Positive & Negative & Positive & Negative \\
\hline 6 & Positive & Negative & Positive & Negative \\
\hline 7 & Positive & Negative & Negative & Negative \\
\hline 8 & Positive & Positive & Positive & Negative \\
\hline 9 & Positive & Positive & Positive & Negative \\
\hline 10 & Positive & Positive & Positive & Negative \\
\hline Total & $10 / 10(100 \%)$ & $7 / 10(70 \%)$ & $8 / 10(80 \%)$ & $1 / 10(10 \%)$ \\
\hline
\end{tabular}

demonstrated strong positive staining in 10-20\% of cells, just below our cutoff for positivity, while the remaining case had less than $10 \%$ positive cells. In contrast, p-S6 negative BLBL cases generally had $0-5 \%$ positive cells. Two cases of TLBL were positive for all markers tested, but this pattern was not observed in any B-LBL cases. Only one case of T-LBL and one case of B-LBL were negative for all of the mTOR pathway proteins (p-mTOR, p-p70, and p-S6).

In benign lymphoid tissues (control material), we observed weak to moderate staining for Notch1 in T-cells and nongerminal center B cells. We also observed moderate $\mathrm{p}$ p70 staining in $T$ cells and both germinal center and nongerminal center B-cells and moderate staining for $\mathrm{p}-\mathrm{S} 6$ in T cells but not B cells. No staining for p-mTOR was observed in B- or T-cells in the normal lymphoid tissues we evaluated, but moderate to strong positive staining was observed in a colon cancer specimen used as a positive control.
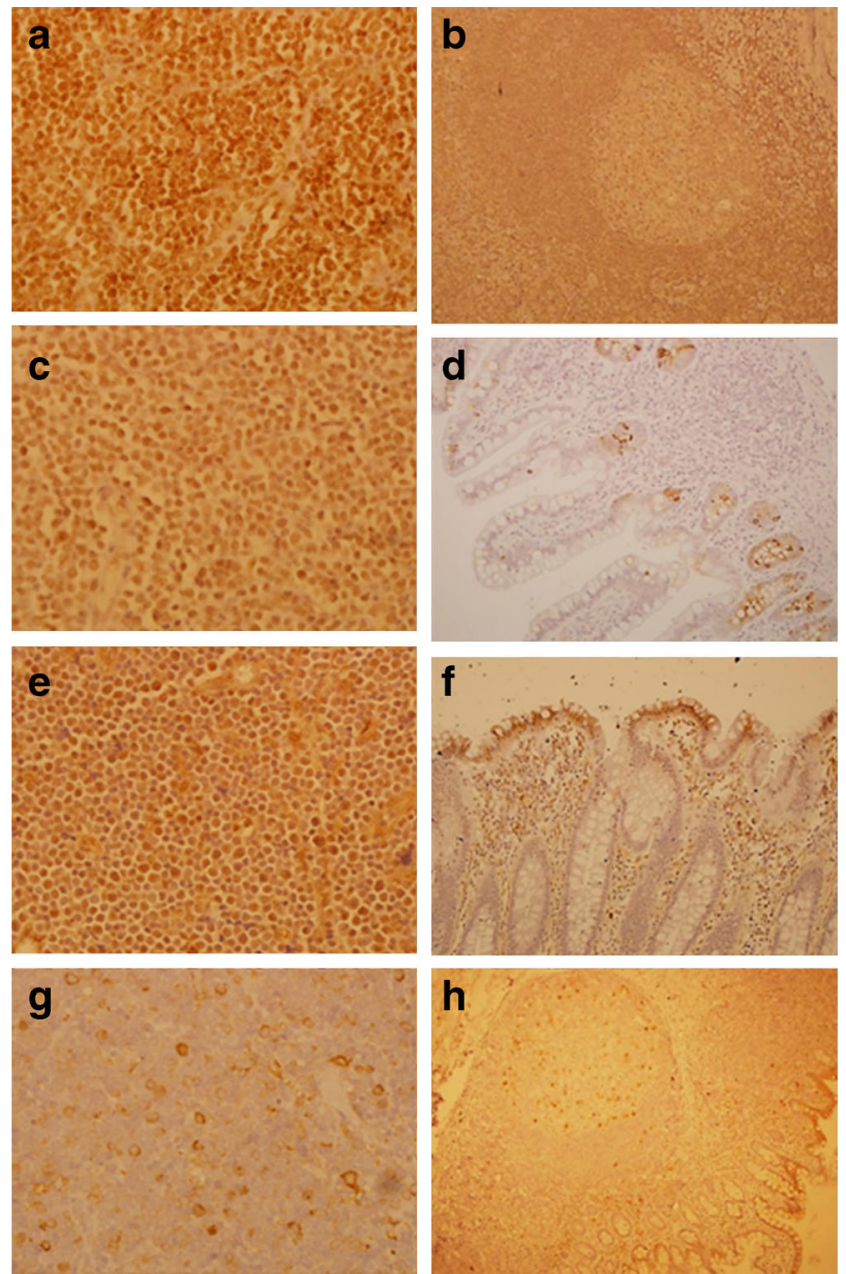

Fig. 2 Representative immunohistochemical staining patterns of cases and control material. Staining localization and intensity are typical of what was seen in most positive cases. a Strong positive staining for Notch1 in T-LBL $(\times 600$, original magnification). b Benign tonsil with reactive follicular hyperplasia (control material) demonstrating weak to moderate staining for Notch1 in T-cells and nongerminal center B cells ( $\times 200$, original magnification). $\mathbf{c}$ Moderate intensity staining for mTOR in T-LBL $(\times 600$, original magnification). d Colonic epithelium (control material) - benign lamina propria lymphocytes stain negative for mTOR, surface epithelium demonstrates negative staining, and crypt epithelium demonstrates strong positive staining $(\times 200$, original magnification). e Moderate intensity staining for p-p70 in T-LBL $(\times 600$, original magnification). f Colonic epithelium (control material) - benign lamina propria lymphocytes demonstrate moderate intensity staining, surface epithelium demonstrates strong positive staining, and crypt epithelium demonstrates negative staining ( $\times 200$ original magnification). g Strong positive staining in approximately $25 \%$ of cells for p-S6 in T-LBL $(\times 600$ original magnification). $\mathbf{h}$ Colonic epithelium (control material) - benign lamina propria lymphocytes demonstrate moderate positive staining, a reactive follicle demonstrates negative staining in the marginal zone and germinal center B-cells $(\times 100$, original magnification $)$

\section{Discussion}

Recent studies have shown that the mTOR pathway is positively regulated by Notch1 signals in T-ALL cells [6]. The Notch family of transmembrane receptors plays a critical role 
in cellular differentiation, proliferation, and apoptosis in numerous cell types, and Notch has been implicated in a variety of malignancies, including hematologic and solid tumors [20-22]. It is known that a subset of T-ALL require constitutive Notch activation for proliferation, and activating mutations in Notch1 are present in 50-60\% of T-ALL cell lines [2]. In this study, we evaluated Notch 1 and the phosphorylated forms of mTOR and downstream targets $\mathrm{p} 70$ and S6 by immunohistochemistry. Staining of the mTOR pathway protein components is predominantly cytoplasmic due to their involvement in translation. However, in our specimens, p-p70 staining appears nuclear and cytoplasmic. It should be noted that cellular localization of staining is difficult to determine in blasts with high nuclear to cytoplasmic ratios. The Notch1 antibody used in this study demonstrates both nuclear and cytoplasmic staining since it recognizes the cytosolic domain of Notch1 when cleaved between Gly1743 and Val1744 that subsequently translocates to the cell nucleus.

The majority of our T-LBL and B-LBL cases demonstrated expression of Notch1, p-mTOR, and p-p70 (in various combinations), but overall expression of p-S6 was low. The results suggest that both the Notch 1 and mTOR pathways are active in pediatric lymphoblastic lymphomas of both T-cell and Bcell lineage. The moderate to strong Notch1 expression is in contrast to the weaker expression seen in normal interfollicular T-cells and nongerminal center B-cells we observed in normal lymphoid tissues, suggesting overexpression in the LBL cases. Although Notch1 was overexpressed in all cases, expression of mTOR pathway proteins was more variable. Overall, $60 \%$ of both the T-LBL and B-LBL cases were positive for both $\mathrm{p}-\mathrm{mTOR}$ and $\mathrm{p}$-p 70, and positive staining of at least one of the mTOR pathway components was present in all but two cases (one T-LBL and one B-LBL) that were negative for p-mTOR, p-p70, and p-S6. No specific patterns were identified when only one or two mTOR pathway components were positive. The findings suggest that Notch 1 activity is upregulated in the majority of these lymphomas and may represent a major pathway leading to cell proliferation and growth and that the mTOR pathway is also active in many cases of LBL. Staining for mTOR pathway components p-p70 and p-S6 (but not p-mTOR) was also seen in benign lymphoid tissues that we evaluated.

Downstream Notch1 signaling may not involve mTOR in all cases, and alternative targets and pathways likely play a role even in cases with active mTOR signaling. Specifically, the lack of p-S6 staining in most cases, even when other mTOR pathway components were expressed, may suggest that another downstream target of mTOR plays a significant role. It is also possible that our cutoff for $\mathrm{p}-\mathrm{S} 6$ positivity was set too high $(\geq 25 \%$ positive cells) since most T-LBL cases that were classified as p-S6-negative demonstrated 10-20\% positive cells. p-S6-negative B-LBL cases generally had very little to no staining.
Although we observed overexpression of Notch 1 in $100 \%$ of our cases, Notch1 activating mutations have been reported in only $50-60 \%$ of T-ALL cases [2]. Notch1 genetic status was not available for our cases. However, overexpression of Notch1 in the absence of a mutation may be due to disruption of usual regulatory pathways leading to overproduction, increased stability, or decreased degradation of Notch1. In addition, translocations involving the Notch1 gene (9q34) have been reported in T-ALL and T-LBL, which are thought to result in aberrant expression of transcription factors, contributing to development of malignancy [23].

One possible intermediary linking the Notch1 and mTOR pathways in LBL is c-Myc, a proto-oncogene involved in cellular growth, which has been identified as a downstream target of Notch1 [4, 6, 24]. A previous study from our group documented high expression of cMYC protein in 17 of $22(77 \%)$ T-LBL cases evaluated by immunohistochemistry [25]. In addition, Palomero and co-workers recently showed that Notch-1 and cMyc control a feed-forward loop of transcriptional networks that regulate leukemic cell growth [24]. Occasional cases of T-ALL and T-LBL have c-Myc overexpression due to a chromosomal translocation at $8 \mathrm{q} 24$ [23].

Knowledge of the role of Notch1 and mTOR signaling in ALL and LBL has therapeutic implications [8, 26]. Chan et al. have demonstrated that mTOR is regulated by Notch1 and that the combination of Notch1 and mTOR inhibitors resulted in synergistic inhibition of T-cell growth [6]. Cullion et al. have shown that the combination of Notch1 inhibitors (gamma-secretase inhibitors, GSI) and rapamycin increased apoptosis and inhibited tumor cell growth in a T-ALL model [27]. Clinical trials, such as Children's Oncology Group ASCT0431 (National Cancer Institute identifier NCT00382109), are underway looking at the benefit of adding mTOR inhibitors to ALL therapy. There is also some evidence that mTOR may play a role in precursor B-ALL, since rapamycin has been shown to induce apoptosis in precursor B-ALL lines in vitro, and has in vivo activity in mice with precursor B-cell neoplasms [28].

In conclusion, our data from a small cohort of LBL cases show that Notch1 and mTOR pathway proteins are active in both T- and B-cell LBL. This information helps to further characterize the signaling pathways that are activated in LBLs, and supports further studies in determining the potential therapeutic role of Notch1 and mTOR inhibitors in children and adolescents with LBL.

Conflict of interest statement The authors declare no conflict of interest. 


\section{References}

1. Borowitz MJ, Chan JKC (2008) Precursor lymphoid neoplasms. In: Swerdlow SH, Campo E, Harris NL, Jaffe ES, Pileri SA, Stein H, Thiele J, Wardiman JW (eds) WHO classification of tumours of haematopoietic and lymphoid tissues. IARC Press, France, pp 167176

2. Weng AP, Ferrando AA, Lee W, Morris JP, Silverman LB, SanchezIrizarry C, Blacklow SC, Look AT, Aster JC (2004) Activating mutations of NOTCH1 in human T cell acute lymphoblastic leukemia. Science 306(5694):269-271

3. Arnold DM, Smith JW, Kelton JG (2008) Diagnosis and management of neonatal alloimmune thrombocytopenia. Transfus Med Rev 22(4):255-267. doi:10.1016/j.tmrv.2008.05.003

4. Chong W, Metcalfe P, Mushens R, Lucas G, Ouwehand WH, Navarrete CV (2011) Detection of human platelet antigen-1a alloantibodies in cases of fetomaternal alloimmune thrombocytopenia using recombinant beta3 integrin fragments coupled to fluorescently labeled beads. Transfusion (Paris) 51(6):1261-1270. doi:10.1111/j. 1537-2995.2010.02977.x

5. Curtis BR, McFarland JG (2009) Detection and identification of platelet antibodies and antigens in the clinical laboratory. Immunohematology 25(3):125-135

6. Chan SM, Weng AP, Tibshirani R, Aster JC, Utz PJ (2007) Notch signals positively regulate activity of the mTOR pathway in T-cell acute lymphoblastic leukemia. Blood 110(1):278-286

7. Chapuis N, Tamburini J, Green AS, Willems L, Bardet V, Park S, Lacombe C, Mayeux P, Bouscary D (2010) Perspectives on inhibiting $\mathrm{mTOR}$ as a future treatment strategy for hematological malignancies. Leukemia 24(10):1686-1699. doi:10.1038/leu.2010.170

8. Teachey DT, Grupp SA, Brown VI (2009) Mammalian target of rapamycin inhibitors and their potential role in therapy in leukaemia and other haematological malignancies. Br J Haematol 145(5):569 580. doi:10.1111/j.1365-2141.2009.07657.x

9. Chen W, Drakos E, Grammatikakis I, Schlette EJ, Li J, Leventaki V, Staikou-Drakopoulou E, Patsouris E, Panayiotidis P, Medeiros LJ, Rassidakis GZ (2010) mTOR signaling is activated by FLT3 kinase and promotes survival of FLT3-mutated acute myeloid leukemia cells. Mol Cancer 9:292. doi:10.1186/1476-4598-9-292

10. Costa LJ (2007) Aspects of mTOR biology and the use of mTOR inhibitors in non-Hodgkin's lymphoma. Cancer Treat Rev 33(1):7884

11. Sharma A, Hoeffer CA, Takayasu Y, Miyawaki T, McBride SM, Klann E, Zukin RS (2010) Dysregulation of mTOR signaling in fragile X syndrome. J Neurosci 30(2):694-702. doi:10.1523/ jneurosci.3696-09.2010

12. Zullo A, Iaconis D, Barra A, Cantone A, Messaddeq N, Capasso G, Dolle P, Igarashi P, Franco B (2010) Kidney-specific inactivation of Ofd1 leads to renal cystic disease associated with upregulation of the mTOR pathway. Hum Mol Genet 19(14):2792-2803. doi:10.1093/ hmg/ddq180

13. Xu Q, Simpson SE, Scialla TJ, Bagg A, Carroll M (2003) Survival of acute myeloid leukemia cells requires PI3 kinase activation. Blood 102(3):972-980. doi:10.1182/blood-2002-11-3429

14. Ly C, Arechiga AF, Melo JV, Walsh CM, Ong ST (2003) BCR-ABL kinase modulates the translation regulators ribosomal protein $\mathrm{S} 6$ and 4E-BP1 in chronic myelogenous leukemia cells via the mammalian target of rapamycin. Cancer Res 63(18):5716-5722

15. Pene F, Claessens YE, Muller O, Viguie F, Mayeux P, Dreyfus F, Lacombe C, Bouscary D (2002) Role of the phosphatidylinositol 3kinase/Akt and mTOR/P70S6-kinase pathways in the proliferation and apoptosis in multiple myeloma. Oncogene 21(43):6587-6597. doi:10.1038/sj.onc. 1205923

16. Coiffier B, Ribrag V (2009) Exploring mammalian target of rapamycin (mTOR) inhibition for treatment of mantle cell lymphoma and other hematologic malignancies. Leuk Lymphoma 50(12):19161930. doi:10.3109/10428190903207548

17. Lim MS, Carlson ML, Crockett DK, Fillmore GC, Abbott DR, Elenitoba-Johnson OF, Tripp SR, Rassidakis GZ, Medeiros LJ, Szankasi P, Elenitoba-Johnson KS (2009) The proteomic signature of NPM/ALK reveals deregulation of multiple cellular pathways. Blood 114(8):1585-1595. doi:10.1182/blood-2009-02-204735

18. Leseux L, Hamdi SM, Al Saati T, Capilla F, Recher C, Laurent G, Bezombes C (2006) Syk-dependent mTOR activation in follicular lymphoma cells. Blood 108(13):4156-4162. doi:10.1182/blood2006-05-026203

19. Abromowitch M, Termuhlen A, Chang M, Perkins SL, Gross T, Weinstein HJ, Finlay J (2008) High-dose methotrexate and early intensification of therapy do not improve 3 year EFS in children and adolescents with disseminated lymphoblastic lymphoma. Results of the Randomized Arms of COG A5971. ASH Annual. Meet Abstr 112(11):3610

20. Chang HH, Lee H, Hu MK, Tsao PN, Juan HF, Huang MC, Shih YY, Wang BJ, Jeng YM, Chang CL, Huang SF, Tsay YG, Hsieh FJ, Lin KH, Hsu WM, Liao YF (2010) Notch1 expression predicts an unfavorable prognosis and serves as a therapeutic target of patients with neuroblastoma. Clin Cancer Res 16(17):4411-4420. doi:10.1158/ 1078-0432.ccr-09-3360

21. Kochert K, Ullrich K, Kreher S, Aster JC, Kitagawa M, Johrens K, Anagnostopoulos I, Jundt F, Lamprecht B, Zimber-Strobl U, Stein H, Janz M, Dorken B, Mathas S (2010) High-level expression of Mastermind-like 2 contributes to aberrant activation of the $\mathrm{NOTCH}$ signaling pathway in human lymphomas. Oncogene. doi:10.1038/ onc. 2010.544

22. Pistollato F, Rampazzo E, Persano L, Abbadi S, Frasson C, Denaro L, D'Avella D, Panchision DM, Della Puppa A, Scienza R, Basso G (2010) Interaction of hypoxia-inducible factor-1alpha and Notch signaling regulates medulloblastoma precursor proliferation and fate. Stem Cells 28(11):1918-1929. doi:10.1002/stem.518

23. Lones MA, Heerema NA, Le Beau MM, Sposto R, Perkins SL, Kadin ME, Kjeldsberg CR, Meadows A, Siegel S, Buckley J, Abromowitch M, Kersey J, Bergeron S, Cairo MS, Sanger WG (2007) Chromosome abnormalities in advanced stage lymphoblastic lymphoma of children and adolescents: a report from CCG-E08. Cancer Genet Cytogenet 172(1):1-11

24. Palomero T, Lim WK, Odom DT, Sulis ML, Real PJ, Margolin A, Barnes KC, O’Neil J, Neuberg D, Weng AP, Aster JC, Sigaux F, Soulier J, Look AT, Young RA, Califano A, Ferrando AA (2006) NOTCH1 directly regulates c-MYC and activates a feed-forwardloop transcriptional network promoting leukemic cell growth. Proc Natl Acad Sci U S A 103(48):18261-18266

25. Glade-Bender J, McFarland JG, Kaplan C, Porcelijn L, Bussel JB (2001) Anti-HPA-3A induces severe neonatal alloimmune thrombocytopenia. J Pediatr 138(6):862-867. doi:10.1067/mpd.2001.114029

26. Pulsipher MA, Wall DA, Grimley M, Goyal RK, Boucher KM, Hankins P, Grupp SA, Bunin N (2009) A phase I/II study of the safety and efficacy of the addition of sirolimus to tacrolimus/ methotrexate graft versus host disease prophylaxis after allogeneic haematopoietic cell transplantation in paediatric acute lymphoblastic leukaemia (ALL). Br J Haematol 147(5):691-699. doi:10.1111/j. 1365-2141.2009.07889.x

27. Cullion K, Draheim KM, Hermance N, Tammam J, Sharma VM, Ware C, Nikov G, Krishnamoorthy V, Majumder PK, Kelliher MA (2009) Targeting the Notch1 and mTOR pathways in a mouse T-ALL model. Blood 113(24):6172-6181. doi:10.1182/blood-2008-02136762

28. Saunders PO, Cisterne A, Weiss J, Bradstock KF, Bendall LJ (2010) The mTOR inhibitor RAD001 (Everolimus) synergizes with chemotherapeutic agents, ionizing radiation and proteasome inhibitors in pre-B ALL. Haematologica 96(1):69-77. doi:10.3324/haematol. 2010.026997 